\title{
O DISCURSO REGIONAL NA CONSTITUIÇÃO DA IDENTIDADE DO GAÚCHO
}

Juliane Tatsch é doutoranda em Letras - Estudos Linguísticos na Universidade Federal de Santa Maria/RS.

E-mail: ju.liane12@hotmail.com

Resumo: O trabalho objetiva discutir como o sujeito gaúcho se constitui pela língua. Para abordar a constituição da identidade gaúcha, consideramos a relação entre língua e sujeito no espaço enunciativo da linguagem gauchesca, de modo a evidenciar a formação de um discurso em torno desse "ser gaúcho", significado pela língua que pratica.

\begin{abstract}
Resumen: El presente trabajo tiene como objetivo debatir como el sujetog aucho se constituye através del discurso. Conel objetivo de abordar la constitución de la identidade gaucha,tenemos em cuenta la relación entre lenguaje y sujeto em el espacio enunciativo del lenguajede losgauchos, a fin de demostrar la formación de un discurso en torno a esse "ser gaucho", significado por el lenguaje que usa.
\end{abstract}

\section{1) Introdução}

Este trabalho é fruto de algumas reflexões que vêm sendo permeadas pelo trabalho desenvolvido no mestrado e que tem sua continuidade agora na tese de doutorado. Como tema de nossa proposta de discussão para o doutorado, partimos da possibilidade de apontarmos a constituição de uma linguagem gauchesca, isto é, um dizer do gaúcho.

O estudo, de aporte teórico de antropólogos (Maria Eunice Maciel, Ruben George Oliven), historiadores (Regina Zilberman, Guilhermino Cesar), ensaístas (Moysés Vellinho e Manoelito de Ornellas) e estudiosos da linguagem (Eduardo Guimarães, Verli Petri, Eliana Sturza) analisa a questão da construção da identidade gaúcha através das relações entre sujeito e língua no espaço regional. O tema da identidade gaúcha é recorrente e tem intrigado pela força dessa identidade que se apoia na figura de um gaúcho mítico, oriundo do pampa, região fronteiriça entre Brasil, Argentina e Uruguai. Considera-se esta construção como um processo discursivo que visa a caracterizar o homem gaúcho pela língua e pela identidade regional, explicando de que forma se organiza o vínculo da língua com a identidade e se constitui um processo identitário particular.

Ao aprofundar a questão da constituição desse sujeito pela língua(gem), o presente artigo propõe apontar indícios sobre o modo como a identidade do gaúcho está representada no discurso regional.

\section{2) Aspectos da construção da identidade regional do gaúcho}

A identidade regional do gaúcho é resultado da interação das etnias que estiveram presentes na formação do Estado do Rio Grande do Sul e, foi sendo consolidada ao longo de sua história. Visando demonstrar como o sujeito gaúcho está constituído no discurso regional, partimos de uma noção de sujeito que só existe a partir de um "eu" que produz enunciados em função da existência de um "tu", demonstrando que enunciador gaúcho é esse que se apresenta como sujeito no discurso. 
A configuração do tipo social gaúcho no Rio Grande do Sul foi permeada por condições sócio-históricas e culturais em meio às implicações políticas e sociológicas dos conflitos e guerras de fronteira. Ao analisar o sujeito histórico que definiu e que acabou por identificar todos os habitantes do Rio Grande do Sul, estudiosos de diferentes campos do saber fixaram um personagem que identificaram como o "tipo social ideal" do sul do estado, ou seja, o gaúcho. Este sujeito gaúcho sul-rio-grandense originou-se da miscigenação de nativos, portugueses e espanhóis, resultando como o tipo social de uma região que não se restringe apenas ao território brasileiro.

\begin{abstract}
Historicamente, o gaúcho está ligado aos primórdios da ocupação europeia do Sul do Brasil. Zona de fronteira, o território compreendido por essa região, Uruguai e Argentina foi um dos pontos em que a expansão colonial das duas coroas, espanhola e portuguesa, fez com que estas se chocassem frontalmente, tornando-se palco de lutas de fronteiras que definiram limites territoriais e pertencimentos nacionais. Embora geralmente associada ao pampa (porém indo além do pampa geográfico), essa região foi ocupada na base da grande propriedade criadora de gado. Foi neste cenário marcado pelo binômio gadoguerra que emergiu o gaúcho, a quem conferiu significado (MACIEL, 2001, p. 240).
\end{abstract}

Dentro do discurso histórico e/ou historiográfico rio-grandense, o gaúcho é glorificado como fruto de um passado enaltecido por guerras e lutas fronteiriças com os castelhanos, tendo como cenário as planícies do pampa, transformado em verdadeiro campo de batalha. Com isso, a construção da identidade regional do gaúcho teve como traços característicos o componente militar-fronteiriço e a importância da pecuária na economia da região, o que impulsionou o surgimento da Estância e do Estado. É um processo que se constituiu historicamente e que ajudou a consolidar a construção de um discurso sobre a identidade cultural regional marcada pelo contraste e pela diferença.

Cabe, portanto, esclarecer o que entendemos como identidade, ressaltando que nesse trabalho utiliza-se o conceito de identidade regional, a fim de estabelecer um vínculo entre as noções de pertencimento a um determinado lugar, que é evocada e se faz presente no plano do discurso. Como construção simbólica de pertencimento, a identidade corresponde a um marco de referência imaginária definida pela diferença (LEENHARDT, 2002, p. 30).

Para a configuração de certa imagem do gaúcho como exponente representativo do Rio Grande do Sul contribuíram vários elementos, alguns de procedência popular, como a indumentária descrita e os hábitos e modo de falar apresentados, outros de natureza erudita, como a usual associação com a figura mítica do centauro. (ZILBERMAN, 1985, p. 41). A identidade rio-grandense provém de uma construção histórica que se deu a partir de grupos constituídos localmente ao longo da história, tendo sido produto desde o convívio dos ibéricos de Castela e Portugal, depois africanos, tropeiros, indígenas até a vinda dos imigrantes, sobretudo, alemães e italianos. A diversidade de culturas presente na formação social do Rio Grande do Sul contribuiu para a composição de uma identidade representada, entre outros aspectos, nas expressões linguísticas usadas pelo sujeito gaúcho.

A identidade como construção social baseada em diferenças relaciona-se com as representações sociais e com o imaginário. Mas a criação de uma identidade, 
implicando uma demarcação de territórios, envolve um sentimento em particular: o pertencimento (MACIEL, 2002, p. 192).

Assim, lembramos que a identidade de um povo envolve inúmeros elementos e que não está apenas vinculada a um recorte territorial, mas resgata características de várias etnias e culturas que a ele se agregaram no decorrer da história.

O território rio-grandense enquanto fronteira com o Prata forjou um tipo social característico, o do gaúcho, que seria distinto dos demais tipos sociais do país.

Se o gaúcho é o senhor da fronteira, é a identidade que se forma no entre lugar, no intervalo entre ser brasileiro, uruguaio, argentino, platino, luso e ibero/latino-americano, o que não pode ser mais multicultural. Se o gaúcho antes era tido como vira mundo, vagabundo, ladrão, contrabandista, matreiro, transforma-se em símbolo de luta, de resistência de apegado às raízes, ao telurismo, transforma-se em sinônimo de bravo, aguerrido, defensor das tradições, com coragem para permanecer se transformando constantemente (FIGUEIREDO, 2006, p. 166).

O gaúcho é também considerado como o típico homem do pampa argentino e uruguaio, estabelecendo dessa maneira, um Rio Grande meio português meio espanhol. A construção simbólica da figura do gaúcho espelha a adaptação do termo relativo a um dos tipos humanos que habitavam a região, ocorrendo em razão do processo de busca de afirmação dos espaços platinos que originaram, no século XIX, as regiões do Uruguai, da Argentina e do Rio Grande do Sul na região mais meridional do Brasil. Nesses espaços reconfigurados, o gaúcho é escolhido como herói fundador para simbolizar, como emblema, a saga da domesticação do território através da exaltação da bravura de sua dupla atuação como homem do campo e guerreiro. Na Argentina e no Uruguai, o gaúcho passa a ser considerado símbolo nacional, ao passo que no Rio Grande do Sul é erigido como emblema do regionalismo (BRUM, 2006, p. 41).

O gaúcho é hoje a nomenclatura usada para o nativo do Rio Grande do Sul, ele é o homem chamado gaúcho de todas as querências, do campo, da serra, do mar, da cidade. È o branco, o negro, o amarelo e o índio que se encontram aqui. E, principalmente, para nós brasileiros, gaúcho é o rio-grandense do sul. Gaúcho, no Brasil, é o homem que reconhece o seu Estado e respeita sua terra. É um homem que homenageia seu pago com suas músicas e suas poesias. Estuda a história da sua raça e da sua gente, cultiva seu chimarrão, sua pilcha e suas raízes. É um homem que sabe que ser gaúcho é ser único e aí está a beleza de sê-lo. Sabe ainda que ser gaúcho... é ser gaúcho, tchê! E isto basta (ZATTERA, 1995, p. 93).

Para Maciel (2001), o uso da palavra gaúcho enquanto uma referência identitária serve para afirmar diferenças que estabelecem distinções entre grupos, contribuindo assim para o reconhecimento do grupo ao qual esse "tipo" está relacionado e em referência ao qual ganha sentido.

Do ponto de vista etimológico, a palavra "gaúcho" no vocabulário da língua portuguesa apresenta variadas possibilidades de origem, o que, por sua vez permite várias interpretações, produzindo efeitos de sentido quando enunciada.

Conforme a acepção atribuída por Nunes em seu dicionário, 
[...] o termo gaúcho, vindo do árabe gaûch, designa "o habitante do Rio Grande do Sul. Morador do interior do Rio Grande, dedicado à vida pastoril e às lidas campeiras. Habitante da Argentina e do Uruguai com costumes assemelhados aos dos riograndenses. Também era, primitivamente, chamado de changador, gaudério, desregrado, vagabundo". (NUNES, 1996, p. 211).

Provavelmente, conforme Sturza (2006, p. 113), "a palavra gaúcho foi introduzida no português falado no Rio Grande do Sul no final do século XVIII, para definir um tipo social que era comum à região do Prata e que foi se deslocando para o estado brasileiro ocupando as regiões do Rio Grande do Sul, Argentina e Uruguai”.

Petri aponta que a designação "gaúcho"

[...] vem de um outro lugar, instaura-se ao sul da América, recupera sentidos, transforma-se e passa a significar de diferentes formas através dos tempos, conforme reinvenção imaginária, mas na maioria das vezes nos remete às relações entre o homem e às coisas da terra, caracterizando de forma mais genérica o gaúcho como um ser essencialmente telúrico. Assim, com o passar do tempo, o funcionamento da designação gaúcho ganha outros espaços, abrangendo outros setores (mais urbanizados) da sociedade organizada que antes procurava ignorar ou se opor à sua existência, enquanto representativa do grupo social do Rio Grande do Sul. Essa designação advém da região do pampa (uruguaio e argentino) e vai avançando às fronteiras do Rio Grande do Sul, levando o restante do Brasil a reconhecer essa designação como sinônimo de riograndense-do-sul ou rio-grandense. Estabelece-se, então, uma generalização que silencia o caráter pejorativo que tal denominação produziu até meados do século XIX. É a força representativa do grupo de "gaúchos pampeanos" que acabou emprestando seu nome aos habitantes do Rio Grande do Sul, a partir do início do século XX, seja ele do meio rural ou urbano [...] (PETRI, 2008, p. 230-231).

A identificação do gaúcho como uma figura simbólica se configura numa espécie de garantia para a afirmação e o desenvolvimento do Rio Grande do Sul (BRUM, 2006, p. 51). A relação do passado com o presente através da ressemantização da palavra "gaúcho" ao longo dos anos, tem seu fio condutor na permanência do tipo humano campesino nas regiões do Prata e na conservação de alguns de seus hábitos tradicionais.

O gaucho depois passou à forma atual gaúcho, sendo, no princípio, uma designação que nos remete a um "preador" de gado xucro e ladrão de estâncias; o que se transformou, na atualidade, numa designação que nos remete ao homem que está intimamente ligado às coisas da terra, enfim, à atividade da pecuária (PETRI, op. cit., p. 126).

No entanto, para Golin (2004), o gaúcho integra um povo forte e ordeiro, associado a uma identidade regional, por isso refere a um tipo social de uma região geográfica muito particular. As relações estabelecidas entre os grupos sociais dessas áreas geograficamente contíguas, durante o processo de formação do Estado gaúcho contribuíram, de acordo com Nunes (1996), para a configuração desse tipo social representativo do Rio Grande do Sul, desenvolvendo um sentimento profundo de liberdade individual como consequência do que era a vida do homem nômade, 
originalmente um rebelde e, muitas vezes foragido da lei, mas com uma inegável expressão de valor e coragem.

Tais elementos presentes na formação social do Rio Grande do Sul diferem daqueles que originaram a dos outros estados do país. Para Cesar (1980), a extração de couros e a salga da carne implantaram, no estuário platino, um gênero de trabalho e um estilo social que vão condicionar o aparecimento dos gaudérios, gente nômade e aventurosa, que, nos moldes da vida rústica, da pilhagem e do contrabando, funde o gaúcho platino, do qual o nosso herdou alguns traços.

O gaúcho sul-rio-grandense constituiu-se como um homem resistente na adversidade, alegre, leal, um cavaleiro que preza acima de tudo a liberdade adquirida nas vastas planícies das regiões campeiras. Ornellas (1999) ressalta que o gaúcho apareceu em condições sociais determinadas pela ausência de um conceito inerente à vida civil, o de propriedade. Criado na liberdade absoluta da natureza, não concebia ele a propriedade de outra forma senão como um atentado a seu domínio e direito.

Essa figura

[...] alimentada e enriquecida pela legenda, ia projetar-se no tempo e ganhar espaço, já agora liberta de seus caracteres primitivos, e acabaria como por uma espécie de mimetismo sociológico, absorvendo na sua estrutura moral todos os rio-grandenses identificados com a terra não só por filiação histórica, mas ainda por aculturação ou adesão afetiva. (VELLINHO, 1962, p. 118).

A partir do final do século XIX, após esse processo de ressignificação, é que a palavra "gaúcho" passou a designar gentilicamente os nascidos no Rio Grande do Sul, bem como os naturais do interior do Uruguai e de parte da Argentina. Esta designação é por sua vez marcada pela instauração de uma diferença, tal como "ser gaúcho antes de ser brasileiro", contribuindo para a instituição da identidade do sujeito gaúcho que não só surgia nesse cenário, deixando de caracterizar um pequeno grupo social, mas passando a designar todo habitante dessa região. Desde então, a palavra "gaúcho" vai aparecer nos dicionários como sinônimo de sul-rio-grandense, reconhecendo-se, de acordo com Petri (2008, p. 129), "uma generalização que elimina definitivamente o caráter pejorativo que tal denominação produziu até meados do século XIX”. Assim, a construção ou a manutenção desse tipo social análogo se ressemantiza como conceito e se mantém atual nos dias de hoje tanto no âmbito do regional quanto do nacional pela permanência de uma identidade gaúcha.

Dessa maneira, a imagem construída historicamente do gaúcho influi diretamente na representação de sua identidade. Entretanto, a construção da identidade como expressão de uma cultura e de um modo de vida surge, conforme afirma Golin (1983), como reflexo de um perfil marcado pelo tradicionalismo gauchesco enquanto expressão de uma distinção cultural. De tal modo, observamos que a identidade regional passa a constituir um meio de diferenciação, uma adoção de valores que representa o sujeito gaúcho enquanto pertencente a um grupo social específico. Essa identidade não é mais um símbolo de atraso e "grossura" ou marginalidade - como ocorreu inicialmente com o gaúcho - mas um objeto estético que, ao ser ressemantizado como conceito permitiu um enriquecimento cultural [...] (FIGUEIREDO, p. 164, 2006). 
Nessa perspectiva, no processo de construção, afirmação e reconstrução de uma identidade social, determinados elementos culturais (traços, manifestações, práticas, etc.) podem se transformar em marcadores identitários, apropriados e utilizados pelo grupo social como sinais diacríticos, símbolos de uma identidade reivindicada, tornando-se emblemas de identificação de uma determinada população que os utiliza (MACIEL, p. 191, 2002).

Pelo exposto, observamos que a trajetória histórica do vocábulo gaúcho apresenta uma mudança em sua significação. Da construção do mito, marcado pelo folclore e cristalizado pela tradição, essa figura tal como a conhecemos hoje, foi elaborada e reelaborada ao longo do tempo, perdendo sua conotação originariamente pejorativa, até adquirir o atual significado gentílico representativo dos habitantes do Estado. Reavalia-se, então, seu significado histórico para transformá-lo no símbolo de identidade regional. O gaúcho é então, o modelo humano escolhido para corporificar o morador do Rio Grande do Sul. Expressão do tipo social rio-grandense resultante da tradição local.

Portanto, seja o gaúcho considerado um símbolo nacional, configurado como um tipo social representativo do Rio Grande do Sul que reconhece na língua a construção da sua identidade ou simplesmente pela instauração de um imaginário sobre o gaúcho, reiteramos que muito de sua constituição é esclarecida sempre a partir desse tipo gentílico que futuramente terá suas características e costumes escolhidos e retomados para a instauração de tradições históricas reafirmadas pelo modo gaúcho de dizer língua e nação. Tradições estas muitas vezes inventadas para a manutenção deste símbolo ou o que a ele se remete.

\section{1) A língua como elemento instaurador e representativo da cultura e do sujeito gaúcho}

Para abordar a constituição da identidade gaúcha, consideramos a relação entre língua e sujeito no espaço enunciativo ${ }^{1}$ da linguagem gauchesca, de modo a evidenciar a formação de um discurso em torno desse "ser gaúcho", significado pela língua que usa.

A língua é um símbolo de identidade que nos permite reconhecer-nos como naturais de uma cidade, de uma região, de um país e, ao mesmo tempo, identificar a quem não o é. Considera-se essa construção como um processo discursivo que significa o sujeito gaúcho pela língua e com isso sua vinculação com uma identidade regional. Nos modos de significar essa relação língua e sujeito explicitam-se processos identitários em constituição. Essa relação constitui-se como um ponto crucial para a construção de identidades segundo o modo como a língua funciona na enunciação desse sujeito gaúcho. Assim, lembramos que a identidade de um povo envolve inúmeros elementos e que não está apenas vinculada a um recorte territorial, mas resgata características de várias etnias que a ele se agregaram no decorrer da história.

\footnotetext{
${ }^{1}$ Guimarães (2002) define que o espaço de enunciação se constitui pela relação que se estabelece entre o falante e a(s) língua(s).
} 
No caso do Rio Grande do Sul, a "coisa" regional decorreu, principalmente, de um desejo oculto de pertencimento a uma identidade brasileira diversa por sua origem fronteiriça e culturalmente híbrida. A ambivalência do movimento de absorção de imaginários estrangeiros, combinando traços da cultura portuguesa, acentuados pelo contato permanente com os platinos, volta-se para a construção de uma identidade própria que busca, no entanto, integrar-se ao resto do país (CAMANI, STURZA, 2010, p. 57).

A língua constitui-se como um ponto crucial para construção de identidades segundo o modo como a língua funciona na enunciação desse sujeito gaúcho. A identidade linguística passa, então, a ser delineada a partir de determinados grupos culturais ou sociais estabelecidos histórico-socialmente, nesse caso, a partir da presença portuguesa e espanhola desde os períodos do descobrimento, conquista e colonização latino-americana, foram sendo construídos traços que significam a língua hoje falada pelos gaúchos. A partir disso, a diversidade de culturas presente na formação social do Rio Grande do Sul contribuiu para a composição de uma identidade cujos traços característicos têm representatividade no dizer dos sujeitos que vivem nesse contexto sul-rio-grandense. A linguagem gauchesca traduz as marcas da identidade regional como construção simbólica de pertencimento. A formação identitária do gaúcho se vê representada na língua, nos seus mecanismos linguísticos e discursivos. A linguagem conta a própria história do gaúcho e define a sua identidade.

A língua é o que simboliza a construção de uma origem particular do tipo humano gaúcho, desempenhando um papel significativo para a identidade gaúcha. Essa identidade adquire sentido por meio da linguagem e dos sistemas simbólicos pelo quais elas são representadas (WOODWARD, 2009, p. 8).

A representação inclui as práticas de significação e os sistemas simbólicos por meio dos quais os significados são produzidos, posicionando-nos como sujeito. É por meio dos significados produzidos pelas representações que damos sentido à nossa experiência $\mathrm{e}$ àquilo que somos (Ibid. p, 17).

Ainda, em consonância com a autora, podemos dizer que a identidade é marcada por meio de símbolos; por exemplo, o laço, as boleadeiras, o pingo, o mate amargo, o churrasco, a indumentária que ficaram como símbolo para o livre filho do Rio Grande do Sul, o gaúcho. Estes elementos, neste caso, funcionam como um significante importante da diferença e da identidade.

Nessa perspectiva, no processo de construção, afirmação e reconstrução de uma identidade social, determinados elementos culturais (traços, manifestações, práticas, etc.) podem se transformar em marcadores identitários, apropriados e utilizados pelo grupo social como sinais diacríticos, símbolos de uma identidade reivindicada, tornando-se emblemas de identificação de uma determinada população que os utiliza. Um simples traço serve, às vezes, para efetuar esta distinção: uma peça de vestuário tradicional, uma palavra ou então uma maneira de fazer um instrumento, os quais, ligados a uma rede de significações, servem para afirmar uma distinção e tornam-se, assim, marcadores de identidade. (MACIEL, p. 191-192, 2002). 
Nessa perspectiva, podemos compreender que o modo como uma sociedade, um povo, produzem sentidos historicamente encontra-se marcado em sua linguagem, no modo como ele fala a "sua" língua, ou melhor, a língua que lhe é dada falar por sua história.

Desse modo, consideramos a língua não como um instrumento para a comunicação, mas como constitutiva de sentidos dessa identidade regional, na medida em que o sujeito ou grupo social se distribui politicamente pela língua. Os falantes atuam como figuras políticas "divididos por seus direitos ao dizer e aos modos de dizer" (GUIMARÃES, 2002, p. 18), sendo assim, espaços políticos.

Seus valores e suas crenças culturais estão significados de diferentes maneiras toda vez que o sujeito faz funcionar a língua que pratica. Assim, trabalhamos com a noção de identidade enquanto constituição de um tipo social que vai ser significado também pela língua.

Sendo um ser simbólico, o homem, enquanto sujeito, é antes de tudo um sujeito que se constitui na e pela linguagem em processos que são históricos. Assim, tomamos a noção de sujeito atrelada à de falante e "os falantes são estas pessoas enquanto determinadas pelas línguas que falam (...). São sujeitos da língua enquanto constituídos por este espaço de línguas e falantes" (GUIMARÃES, 2003, p. 10).

É pela inscrição do sujeito na história que sabemos que somos sujeitos de algum lugar e, do mesmo modo, que, sem língua, não há história nem memória. O terreno da língua como espaço de movimentação/produção/reprodução da história e da identidade de um grupo social acaba revelando as várias facetas desse sujeito gaúcho. Um enunciador gaúcho, que também se marca na língua e, por consequência, se representa enquanto discurso de uma identidade regional. Temos a presença de um locutor que está inserido num lugar social; um enunciador que enuncia a partir do ponto de vista do gaúcho. A língua é então materializada no dizer por um sujeito que se designa e se subjetiva como "eu" na linguagem. Um sujeito que ao enunciar, está significando a relação das línguas e de seus falantes.

Essa imagem que consolida o homem gaúcho contribui para a formação de um modo gauchesco que expressa a identificação de cada sujeito no espaço sul-riograndense, efetivamente num espaço bem determinado: o campo (a campanha) gaúcho. Tal sujeito representa um tipo social resgatado nas suas origens, um gaúcho do campo, que vive em seu mundo gauchesco e que representa pela linguagem o gaúcho e a história do Estado. Assim, se constitui, se define e se identifica através das línguasculturas escolhidas por ele.

As identidades modernas não podem ser definidas como únicas, mas como pertencimento a certas posições históricas, raciais, étnicas, linguísticas, ou seja, diversas e plurais, gerando a tensão entre identidades globais e locais.

Para Oliven "as identidades são construções sociais formuladas a partir de diferenças reais ou inventadas que operam como sinais diacríticos, isto é, sinais que conferem uma marca de distinção" (2006, p. 34). Ainda, para o autor (op. cit.), "as primeiras vivências e socializações culturais são cruciais para a construção das 
identidades sociais, sejam elas étnicas, religiosas, regionais ou nacionais". Quando se fala em construção de identidades, quando se analisa esse processo, deve-se compreender que a linguagem característica de cada região entra na discussão automaticamente. As línguas são a própria expressão das identidades de quem delas se apropria.

A língua é mobilizada pelo sentido em um espaço discursivo ao qual a construção da identidade do sujeito gaúcho está assegurada. Essa análise discursiva advém da relação entre sujeito e língua. Além disso, revela ou evidencia a produção e efeitos de sentidos da linguagem, uma vez que esses efeitos, na linguagem, significam histórica e politicamente (ORLANDI, 2006).

Para Rajagopalan a identidade está vinculada à língua, e afirma que:

A identidade de um indivíduo se constrói na língua e através dela. Isso significa que o indivíduo não tem uma identidade fixa anterior e fora da língua. Além disso, a construção da identidade de um indivíduo na língua e através dela depende do fato de a própria língua em si ser uma atividade em evolução e vice-versa. Em outras palavras, as identidades da língua e do indivíduo têm implicações mútuas. Isso significa que as identidades em questão estão sempre num estado de fluxo (RAJAGOPALAN, 1998, p. 41-42).

Partindo então do pressuposto de que a língua constitui-se como um elo de identificação de um determinado grupo perante outros, trabalhamos neste estudo apenas com a ideia de identidade relacionada com a linguagem, como constitutiva na e pela língua, possibilidades de sentidos, de produção de sentidos. Nessa perspectiva, propomos refletir sobre a relação sócio-histórica estabelecida entre língua e sujeito num espaço enunciativo próprio que constitui por sua vez discursos na e sobre a língua, bem como evidencia a língua como instauradora e representativa da cultura que a ela está relacionada.

\section{3) Considerações Finais}

A identidade regional do gaúcho é resultado da interação das etnias que estiveram presente na formação do Estado do Rio Grande do Sul e foi sendo consolidada ao longo de sua história. Visando demonstrar como o sujeito gaúcho está constituído e representado no discurso regional, partimos de uma noção de sujeito que só existe a partir de um "eu" que produz enunciados em função da existência de um "tu", demonstrando que enunciador gaúcho é esse que se apresenta como sujeito no discurso e procura expressar uma dada identidade regional.

Essa relação constitui-se como um ponto crucial para a construção de identidades segundo o modo como a língua funciona na enunciação desse sujeito gaúcho. Assim, retomamos que a identidade de um povo envolve inúmeros elementos e que não está apenas vinculada a um recorte territorial, mas resgata características de várias etnias que a ele se agregaram no decorrer da história. Partindo dessa premissa, consideramos que as manifestações linguísticas do sujeito gaúcho fazem parte de um espaço de enunciação específico, fazendo com que apresentem sentidos diferenciados 
de outros espaços enunciativos, e que seus sentidos são construídos por uma confrontação de línguas na configuração de um espaço próprio.

A linguagem gauchesca traduz as marcas da identidade regional como construção simbólica de pertencimento. A formação identitária do gaúcho se vê representada na língua, nos seus mecanismos linguísticos e discursivos. Assim, a identidade é considerada como construção simbólica de pertencimento e que corresponde a um marco de referência imaginária que se define pela diferença.

Assim, através desses conceitos evidenciamos a construção da representação de um tipo social projetada no espaço regional e que servirá de base para a formulação de uma identidade perpetuada nos dias de hoje e reafirmada em diferentes expressões culturais. Temos, portanto, a configuração de um tipo social que representa uma imagem do gaúcho e que emerge numa construção imaginária evocada para significar a identidade desse sujeito gaúcho.

\section{4) Referências}

BRUM, Ceres Karam. "Esta terra tem dono": representações do passado missioneiro no Rio Grande do Sul. Santa Maria/RS: Ed. da UFSM, 2006.

CAMANI, Emanuele; STURZA, Eliana. Entre lusos y castellanos: discursos sobre lengua, cultura y etnia enla historia do Rio Grande do Sul. In: Estudos hispânicos: história, língua e literatura. CARDOSO, Rosane; DUTRA, Eduardo. (Orgs.) Santa Cruz do Sul: EDUNISC, 2010.

CESAR, Guilhermino. Primeiros cronistas do Rio Grande do Sul. Porto Alegre, RS: EDURGS, 1980.

FIGUEIREDO, Joana Bosak de. Fronteiras no Prata: guachos e sombras. A identidade gaúcha e a literatura de Barbosa Lessa e Ricardo Güiraldes. In: CHIAPPINI, Ligia; MARTINS, Maria Helena (Org.). Cone Sul: fluxos, representações e percepções. São Paulo: Hucitec, 2006.

GOLIN, Tau. Identidades: questões sobre as representações socioculturais no gauchismo. Passo Fundo: Clio, Méritos, 2004.

GUIMARÃES, Eduardo. A marca do nome. Revista $R U A, \mathrm{n}^{\circ}$ 9. Campinas, SP: Unicamp, p. 19-31, 2003.

Semântica do Acontecimento: um estudo enunciativo da designação. São Paulo, Campinas: Pontes, 2002.

LEENHARDT, Jacques. Fronteiras, fronteiras culturais e globalização. In: MARTINS, Maria Helena (Org.). Fronteiras Culturais - Brasil - Uruguai - Argentina. São Paulo: Ateliê, 2002.

LOIS, Élida. Cruzamento(s) de fronteira(s). In: In: CHIAPPINI, Ligia; MARTINS, Maria Helena; PESAVENTO, Sandra Jatahy. Pampa e cultura: de Fierro a Netto. Porto Alegre: Editora da UFRGS, 2004. 
MACIEL, Maria Eunice. A atualização do passado. In: RECKZIEGEL, Ana Luiza Setti; FÉLIX, Loiva Otero (Org.). RS: 200 anos definindo espaços na história nacional. Passo Fundo: UPF, 2002.

Memória, tradição e tradicionalismo no Rio Grande do Sul. In: BRESCIANI, Stella; NAXARA, Márcia. (Orgs.) Memória e (res) sentimento: indagações sobre uma questão sensível. Campinas, SP: Editora da Unicamp, 2001.

NUNES, R. C.; NUNES, Z. C. Dicionário de Regionalismos do Rio Grande do Sul. 2. ed. Porto Alegre: Martins Livreiro, 1996.

OLIVEN, Ruben George. Fronteiras Culturais. In: CHIAPPINI, Ligia; MARTINS, Maria Helena (Org.). Cone Sul: fluxos, representações e percepções. São Paulo: Hucitec, 2006.

O processo de construção da identidade gaúcha. In: RECKZIEGEL, Ana Luiza Setti; FÉLIX, Loiva Otero (Org.). RS: 200 anos definindo espaços na história nacional. Passo Fundo: UPF, 2002.

ORNELLAS, Manolito de. Gaúchos e beduínos: a origem étnica e a formação social do Rio Grande do Sul. $4{ }^{\text {a }}$ Ed. Martins Livreira, Porto Alegre, RS, 1999.

PETRI, Verli. A produção de efeitos de sentidos nas relações entre língua e sujeito: um estudo discursivo da dicionarização do gaúcho. Letras, Santa Maria, v. 18, n. 2, p. 227-243, jul./dez. 2008.

RAJAGOPALAN, K. O conceito de identidade em linguística: é chegada a hora para uma reconsideração radical? In: SIGNORINI, I. (Org.). Lingua(gem) e identidade: elementos para uma discussão no campo aplicado. Campinas: Mercado de Letras; São Paulo: Fapesp, 1998.

STURZA, Eliana Rosa. Vocabulário sul-rio-grandense: De Instrumento Linguístico à Constituição de um Discurso Fundador. Campinas, SP: Universidade Estadual de Campinas: Pontes Editores, 2006. (Letras e Instrumentos Linguísticos, n. 18, p. 101121, jul./dez.2006).

VELlinhO, Moysés. O Rio Grande e o Prata: contrastes. Porto Alegre: Globo, 1962.

WOODWARD, Kathryn. Identidade e diferença: uma introdução teórica e conceitual. In: SILVA, Tomaz Tadeu da. (Org). Identidade e diferença: a perspectiva dos estudos culturais. Petrópolis, RJ: Vozes, 2009.

ZATTERA, Véra Stedile. Gaúcho: iconografia (séculos XIX e XX). Porto Alegre: Pallotti, 1995.

ZILBERMAN, Regina. Literatura gaúcha: termos e figuras da ficção e da poesia do Rio Grande do Sul. Porto Alegre: L\&PM, 1985. 